\title{
Lipid Mobilization and Acid Phosphatase Activity in Lytic Compartments during Conidium Dormancy and Appressorium Formation of Colletotrichum graminicola
}

\author{
Ruth Janice Guse Schadeck*, Breno Leite*, ${ }^{* * \dagger}$ and Dorly de Freitas Buchi* \\ *Department of Cellular Biology, Federal University of Paraná, C.P. 19031, 81531-970, Curitiba, PR, Brazil \\ and ${ }^{* *}$ Department of Biochemistry, Federal University of Paraná, C.P. 19046, 81531-970, Curitiba, PR, Brazil
}

Key words: acid phosphatase/vacuoles/lipid/fungi/germination

\begin{abstract}
Colletotrichum graminicola, a pathogen of sorghum and corn, was investigated prior and during germination as to certain aspects of acid phosphatase activity and lipid mobilization. Ungerminated conidia cytoplasm was filled with lipid deposits, which were mobilized during the germination process. Cytochemical ultrastructural examination showed that conidia vacuoles exhibit acid phosphatase activity, which is suggestive of lytic activity. Lipid bodies, stored in the ungerminated conidia cytoplasm, were internalized by vacuoles in a process analogous to microautophagy and were apparently digested inside them. The lipid bodies disappeared and vacuoles became enlarged in conidial cells during germination. Appressoria also showed acid phosphatase activity in multiple heterogeneous vesicles which were, in most cases, juxtaposed with lipid bodies. These results suggest that the vacuolar system plays an important role during $C$. graminicola germination and that the initial stages of lipid metabolization are taking place inside the vacuoles.
\end{abstract}

The conidium of Colletotrichum graminicola is the causal agent of anthracnose of cereals and grasses. It is embedded in a mucilage (26) which exhibits high concentrations of the secondary metabolite mycosporinealanine, responsible for self-inhibition of conidia germination (17). In $C$. graminicola conidia, the main endogenous nutritional reserve is constituted of lipid bodies, which fill most of the young conidia cytoplasm (23). Previous studies demonstrated that the lipid content decreases during aging with concomitant cytoplasmic vacuolation $(16,23)$. Large lipid globules were also shown in the appressoria of $C$. graminicola germinated on maize and oat leaves $(29,30)$. Lipid bodies digestion inside of the fungal vacuoles was suggested (39). Fungal and yeast vacuoles were often regarded as cellular structures analogous to lysosomes $(2,11,13,31)$. Although macromolecule degradation is an important function of these organelles, vacuoles are also involved in a variety of other cellular activities, for example, in compartmentalization of metabolites and cytosolic ion and $\mathrm{pH}$ homeostasis (15). Yeast vacuoles, the most studied, exhibit several hydrolytic enzymes such as proteinases, aminopeptidase I and $\alpha$-mannosidase (15).

Corresponding author current address: Dr. Breno Leite, Departamento de Fitopatologia (NAP/MEPA)-ESALQ/USP, Caixa Postala, CEP 13418-900, Piracicaba, SP, Brazil.

E-mail: bleite@carpa.ciagri.usp.br
Acid phosphatase is a vacuolar hydrolase of several fungi $(2,13,32)$. This enzyme generates orthophosphate as a result of hydrolysis of the organic phosphate (8) and, in different organisms, has been used as a marker for lysosomal structures $(9,33)$. Vacuolation of the appressoria was observed during fungal germination $(22,28)$, including that of $C$. graminicola germinated on maize leaves (30). In the present investigation we demonstrate the acid phosphatase activity in the vacuolar system of ungerminated conidia, germinated conidia and appressoria, and we also describe the mechanism of lipid bodies uptake by ungerminated conidia vacuoles.

\section{MATERIALS AND METHODS}

\section{Growth of the fungus}

Colletotrichum graminicola (teleomorph $=$ Glomerella graminicola-Politis) (Ces.) Wils., isolate CgM2 was provided by Dr. R.L. Nicholson (Host Parasite Interaction Laboratory, Purdue University, West Lafayette, IN., USA). Conidia were grown at $22^{\circ} \mathrm{C}$ under constant fluorescent light on an oatmeal agar medium.

\section{Cell preparation}

Conidia were harvested from 14-day-old cultures, at maximum germination capacity (17) and washed in distilled water. Cellophane membranes were previously placed on the bot- 
tom of a $50 \mathrm{ml}$ beaker to receive conidia for germination. Subsequently, $10 \mathrm{ml}$ of a conidial suspension $\left(10^{3}\right.$ conidia $\left./ \mathrm{ml}\right)$ were applied over these membranes. Similarly, glass slides were placed on the bottom of a $200 \mathrm{ml}$ beaker and $40 \mathrm{ml}$ of a conidial suspension, at the same concentration, were applied over them. In both cases, the conidial suspension height over germination surfaces were performed at $1 \mathrm{~cm}$. Cells were then incubated at $22^{\circ} \mathrm{C}$ for $16 \mathrm{~h}$ under constant fluorescent light.

\section{Light microscopy of whole cells}

Cells were stained with Sudan III for lipid detection and with fast green for background contrast. Ungerminated and germinated conidia adhering to glass slides were fixed in $4 \%$ formaldehyde for $25 \mathrm{~min}$. Thereafter, conidia were washed with distilled water followed by a hydroalcoholic solution containing $60 \%$ isopropyl alcohol and then stained for lipids with Sudan III for $15 \mathrm{~min}$. The hydroalcoholic stain solution consisted of a $60 \%$ saturated solution of Sudan III in isopropyl alcohol (6). Subsequently, cells were washed with distilled water, stained for $15 \mathrm{~min}$ in a solution containing $0.004 \%$ fast green and $0.04 \%$ acetic acid, washed with distilled water and mounted in glycerine. Staining with fast green was omitted in control cells. The preparations were photographed in Zeiss Axiophot photomicroscope.

\section{Acid phosphatase activity}

Ungerminated conidia and cellophane membranes with germinated conidia and appressoria were fixed with $1 \%$ glutaraldehyde in $0.1 \mathrm{M}$ cacodylate buffer $\mathrm{pH} 7.2$ containing $5 \%$ sucrose, for $30 \mathrm{~min}$. The cells were then washed twice in the same buffer, and subsequently twice in $0.1 \mathrm{M}$ Tris maleate buffer $\mathrm{pH} 5.5$ containing $5 \%$ sucrose, followed by incubation in the same buffer containing $2 \mathrm{mM}$ sodium glycerophosphate (substrate) and $2 \mathrm{mM}$ cerium chloride (phosphate acceptor) for $60 \mathrm{~min}$. After incubation, cells were washed once in the same buffer and once in $0.1 \mathrm{M}$ cacodylate buffer $\mathrm{pH} 7.2$ containing 5\% sucrose and then processed for transmission electron microscopy (21). Cerium phosphate reaction product deposition was used as the parameter for localization of acid phosphatase activity. Control cells were incubated without substrate.

\section{Transmission electron microscopy (TEM)}

Ungerminated conidia and cellophane membranes with germinated conidia and appressoria were fixed for $2 \mathrm{~h}$ in a solution containing $2 \%$ glutaraldehyde, $4 \%$ paraformaldehyde and 5 $\mathrm{mM} \mathrm{CaCl} 2$ in $0.1 \mathrm{M}$ cacodylate buffer $\mathrm{pH}$ 7.2. Cells were then washed in the same buffer and postfixed in a solution containing $1 \% \mathrm{OsO}_{4}, 0.8 \%$ ferrocyanide and $5 \mathrm{mM} \mathrm{CaCl}_{2}$ in $0.1 \mathrm{M}$ cacodylate buffer $\mathrm{pH} 7.2$, dehydrated in a graded series of acetone (15 min each) and embedded in Spurr resin (3). Sections of cytochemical tests were observed without further contrast. The control for lipid bodies was performed by extraction during slow dehydration (30 min each) in the same graded series of acetone, and the sections stained with uranyl acetate and lead citrate.

\section{RESULTS}

\section{Lipid reserves in ungerminated and germinated conidia}

Ungerminated conidia cytoplasm was filled with lipid reserves, which can be observed directly by Sudan III staining (Figs. 1-2). In the whole cells, it was possible to observe individualized fine lipid globules in the cellular periphery (Fig. 1). The presence of lipids in ungerminated conidia was confirmed by ultrastructural studies. The content of lipid bodies in the ungerminated conidia was extracted after slow dehydration in acetone, resulting in electron transparent regions (Fig. 7). These lipid bodies were observed as electron dense bodies at standard dehydration (Figs. 8-13). In appressoria, lipid bodies were observed by light (Fig. 4) and electron microscopy (Figs. 15-16).

\section{Lipid mobilization and vacuolation in the conidia during germination}

The light microscopic observations of the whole cells stained with Sudan III (Figs. 1-6) made possible a study of different stages of germination and its relation with the lipid content inside the conidia. Decrease in lipid deposits and vacuolation in the conidia was observed during germination (Figs. 2-6). The vacuolation of germinated conidia was also verified by electron microscopy, showing that the vacuoles can occupy most of the conidia cytoplasm (Fig. 14). Concomitantly with the lipid decrease, the presence of lipid material inside vacuoles of the conidia became evident during germ tube (Fig. 3) or appressoria (Fig. 5) formation. In later stages of appressorium formation, lipid bodies disappeared in the germinated conidia (Fig. 6). A septum dividing germinated conidia in two parts was verified by light (Fig. 6) and electron microscopy (Fig. 14), and numerous cells demonstrated lipid first decreasing in one half followed by the other half (Fig. 4).

\section{Acid phosphatase activity in ungerminated conidia}

The ungerminated conidium panoramic view (Fig. 8) revealed that the cytoplasmic volume contains a large number of lipid bodies, one nucleus and vacuoles, which display the acid phosphatase reaction product. Vacuoles exhibit cytoplasmic structures uptake and acid phosphatase reaction product associated with the internal face of the vacuolar membrane (Fig. 9). Initial and more advanced internalization stages of different cellular components were observed. Images strongly suggested membrane fusion and vesicle formation, which was introduced inside vacuoles, in the final stages of internalization. Details of the lipid body engulfment are described in figures 10-11. Initially, these bodies ad- 

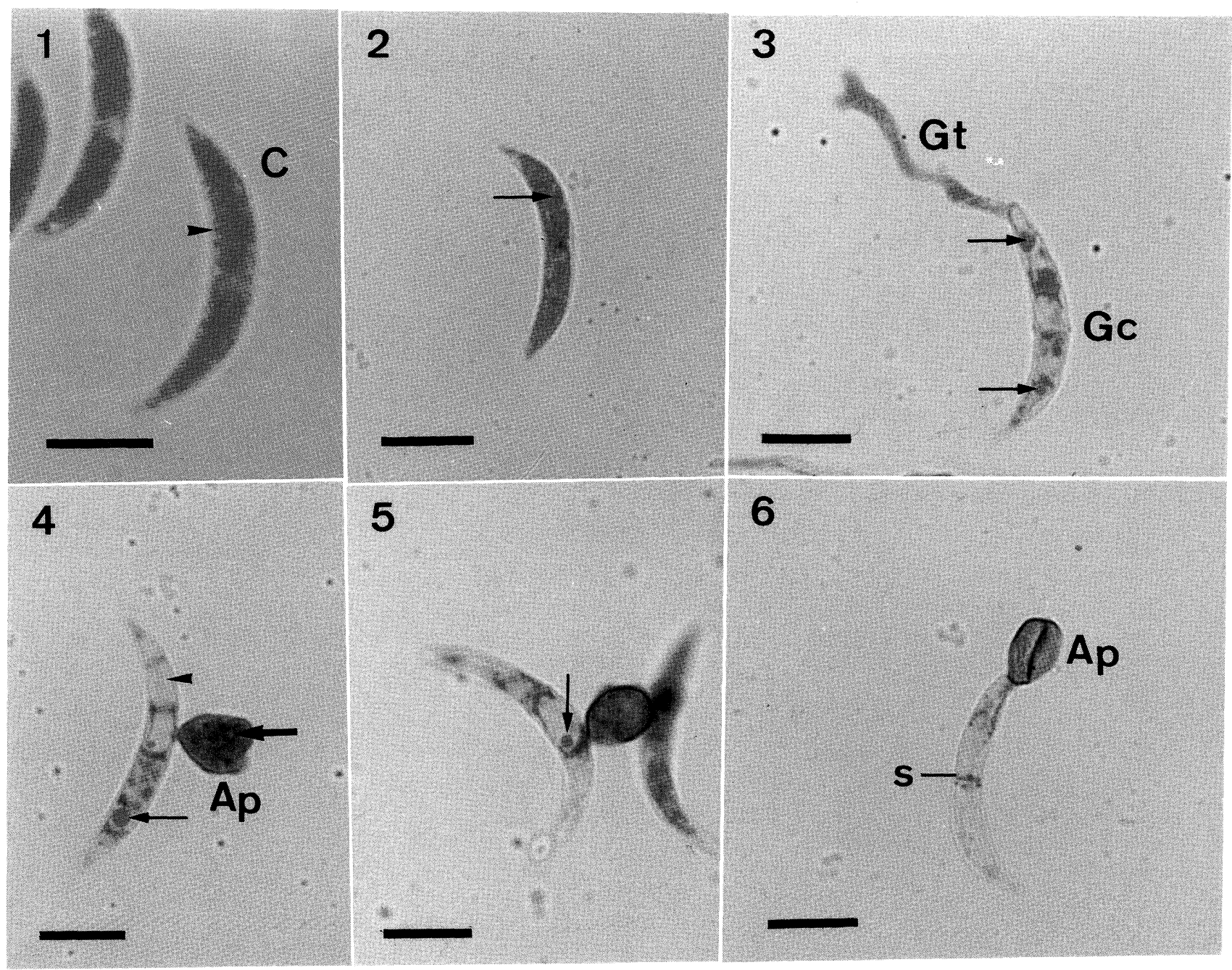

Fig. 1-6.

Fig. 1. Sudan III cytochemical reaction control in whole ungerminated conidium (C) exhibiting cytoplasm replete with lipid (red stained). Note fine lipid granulations in the cytoplasm periphery (arrow tip). Bar $=10 \mu \mathrm{m}$.

Figs. 2-6. Lipid mobilization and vacuolation during germination, demonstrated by Sudan III cytochemical reaction post stained with fast green. Fig. 2. Ungerminated conidium showing cytoplasm completely occupied with lipids (arrow). Fig. 3. Germinated conidium (Gc) exhibiting lipid inside vacuoles (arrows) during germ tube (Gt) formation. Fig. 4. Germinated conidium exhibiting one half proximally empty (arrow tip) and other contained various lipid deposits (arrow). Lipid (thick arrow) can be observed inside the appressorium (Ap). Fig. 5. Germinated conidium exhibiting lipid material inside a vacuole (arrow). Note few lipid deposits in the conidium at this stage. Fig. 6. Germinated conidium exhibited only traces of lipids. Note, at this stage, total melanization of the appressorium (Ap) and the septum (s) that divides germinated conidium. Bars $=10 \mu \mathrm{m}$.

here to the vacuolar membrane which begins to invaginate (Fig. 10). Then, the lipid material is surrounded by vacuolar membrane invaginations and protrusions (Fig. 11). Finally, a recently internalized vesicle containing lipid material was observed inside the vacuole (Fig. 11). Alterations in the engulfed material was verified and include the rupture of the internalized vesicle membrane and diversification of vesicles content (Fig. 12). Control cells, without the substrate, display a similar pattern of cytoplasmic material uptake (Fig. 13). In the control cells, no deposition of reaction product was observed in any cellular structure at any of the monitored developmental stages.

\section{Acid phosphatase activity and vacuolation in germinated conidia}

Germinated conidia presents a large vacuole, that can occupy one half of the germinated conidia separated by a septum (Fig. 14). At this stage of development, the vacuoles also exhibit the reaction product in the lumen 
R.J.G. Schadeck et al.

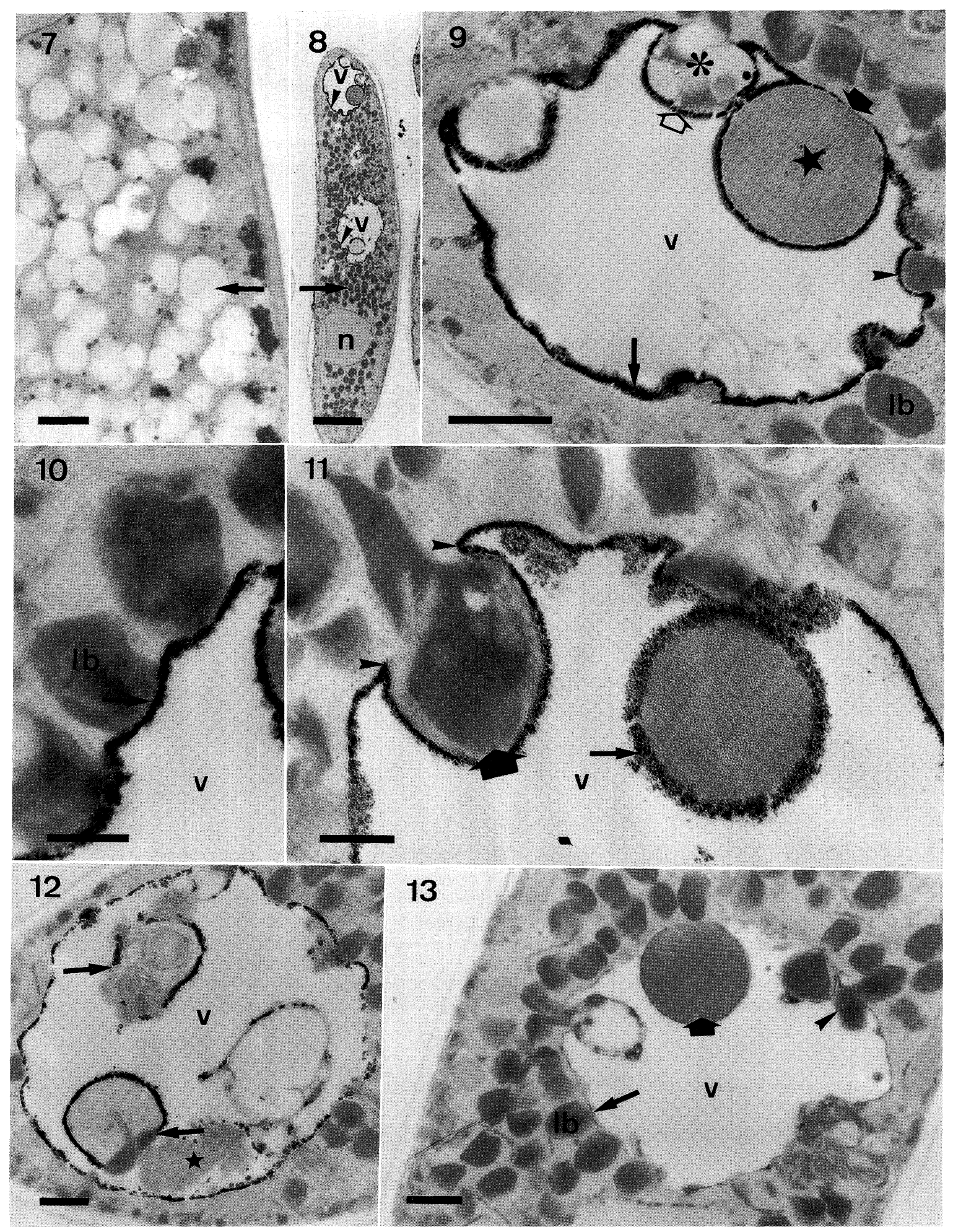

Fig. 7-13. 
and no lipid bodies were observed in the conidia. Diversified vacuolar content, suggesting debris of cellular components, was observed in the lumen.

\section{Acid phosphatase activity in appressoria}

The reaction product was observed as dense deposits inside vesicles. These vesicles were heterogeneous in size and shape and were, in most cases, closely associated with lipid bodies (Figs. 15-16). Large lipid bodies occupy extensive cytoplasmic areas (Fig. 15) and lipid material was observed inside compartments containing the acid phosphatase reaction product (Fig. 16). The product of acid phosphatase was observed inside a vesicle that appeared to release its content, forming a continuous layer at the cellular surface (Fig. 17). The reaction product was also present in the extracellular matrix (Fig. 17). These results suggest secretion of acid phosphatase.

\section{DISCUSSION}

Lipid reserves are broadly found in fungal spores (38). The abundant lipid deposits observed in ungerminated conidia, by different techniques, have been previously demonstrated in C. graminicola by freeze-substitution procedures (23). These authors demonstrated that young conidia cytoplasm was dominated by lipid bodies. Other species of Colletotrichum exhibit a similar pattern of lipid deposits $(14,37)$. In the same way, the lipid globules observed in appressoria were similar to those demonstrated in the appressoria of C. graminicola germinated on the leaves of maize (30). A decreasing conidial lipid content, while the germinating process moves forward, is in agreement with studies which described lipid processing during the germination of different fungi $(7,19,20)$. The vacuolation was observed during aging of $C$. graminicola conidia $(16,23)$. Previous observations demonstrated neutral red uptake by $C$. graminicola conidia (16). In this case, the formed vesicles are apparently transferred to the vacuole interior. Our results demonstrated the presence of lipids inside conidia vacuoles by light microscopy, during different stages of germination, and by electron microscopy, in ungerminated conidia. Lipid engulfment by vacuoles, followed by digestion, was suggested to occur in Botrytis cinerea and Ceratocystis ulmi, as well as for glycogen in Elsinöe wiconsinensis (39). In a similar manner, Kerrigan and Mims (1993) suggested vacuolar lipid uptake in old conidial vacuoles of Colletotrichum gloeosporioides. In ungerminated conidia, the product deposition of the acid phosphatase reaction on the interior surface of the vacuolar membrane (Fig. 9) provided a useful marker for studying the uptake mechanism of cellular components. Our results suggest that the uptake mechanism of lipid bodies and other cellular structures by ungerminated vacuoles is analogous to microautophagy. In this process, cytoplasmic components are directly sequestered inside the vacuole or lysosome by invagination or protrusion of the vacuolar or lysosomal membrane (40). The changes observed in the internalized material are indicative of an ongoing digestive process and was used as parameters of vacuole digestion activity in fungal and plant cells $(12,39)$. Uptake of cytoplasmic structures by vacuoles, followed by digestion, are characteristics of an autophagic process. Recently, autophagy was demonstrated in many strains of yeast. In Saccharomyces cerevisiae, nutrient starvation induces nonselective autophagic degradation in the vacuoles (34). Tuttle and Dunn (1995) demonstrated that the degradation of peroxisomes in Pichia pastoris may be due to a process analogous to microautophagy or macroautophagy, depending on the medium conditions. In the mutant yeast pep-4, when glucose-starved cells were replenished with glucose, degradation of peroxisomes by microautophagy was observed (5).

Vacuoles play an important role in breakdown of macromolecular constituents of yeast and other fungal cells $(15,39)$. However, only a few publications are

\footnotetext{
Fig. 7. Control of lipids in the ungerminated conidium. Electron transparent remains of extracted lipid bodies (arrow) was observed. Bar $=1$ $\mu \mathrm{m}$.

Fig. 8. Ungerminated conidium longitudinal section. The acid phosphatase reaction product (arrow tips) is observed inside vacuoles (v). Note numerous stored lipid bodies (arrow) in the cytoplasm. The nucleus (n) is observed. Bar $=2.5 \mu \mathrm{m}$.

Fig. 9. Higher magnification of an ungerminated conidium vacuole (v). Lipid bodies (lb) in the cytoplasm and deposition of acid phosphatase reaction product at the vacuolar membrane (arrow) are observed. Note the initial membrane invagination (arrow tip), during early stages of a lipid body uptake, and deepening (empty arrow), during a more advanced engulfment stage of diversified structures (asterisk). A vesicle (star), apparently in formation, seems to present a fused membrane region with the vacuole membrane (thick arrow). Bar $=500 \mathrm{~nm}$.

Figs. 10-11. Lipid body uptake by ungerminated conidia vacuoles (v). Fig. 10. Lipid body (lb) adhesion to the external side (arrow) of the vacuole membrane. Note the initial membrane invagination in this area. Bar $=200 \mathrm{~nm}$. Fig. 11. Advanced stages of lipid internalization. Deep invagination involving material to be engulfed (thick arrow) and membrane protrusions (arrow tips) are observed. A recently internalized vesicle (arrow) is shown. Bar $=200 \mathrm{~nm}$.

Fig. 12. Internalized vesicle alterations in an ungerminated conidia vacuole (v). The internalized vesicle contains diversified material and shows ruptures in the membrane (arrows). Free material (star) in the vacuolar lumen is observable. Bar $=500 \mathrm{~nm}$.

Fig. 13. Acid phosphatase control in ungerminated conidium with no reaction product in any cellular structure. Note the adhesion (arrow) of lipid bodies (lb) to the vacuole (v) membrane. Engulfing of cytoplasmic lipid bodies (arrow tip) and internalized material that presents equal electron density of lipid bodies (thick arrow) are verified. Bar $=500 \mathrm{~nm}$.
} 

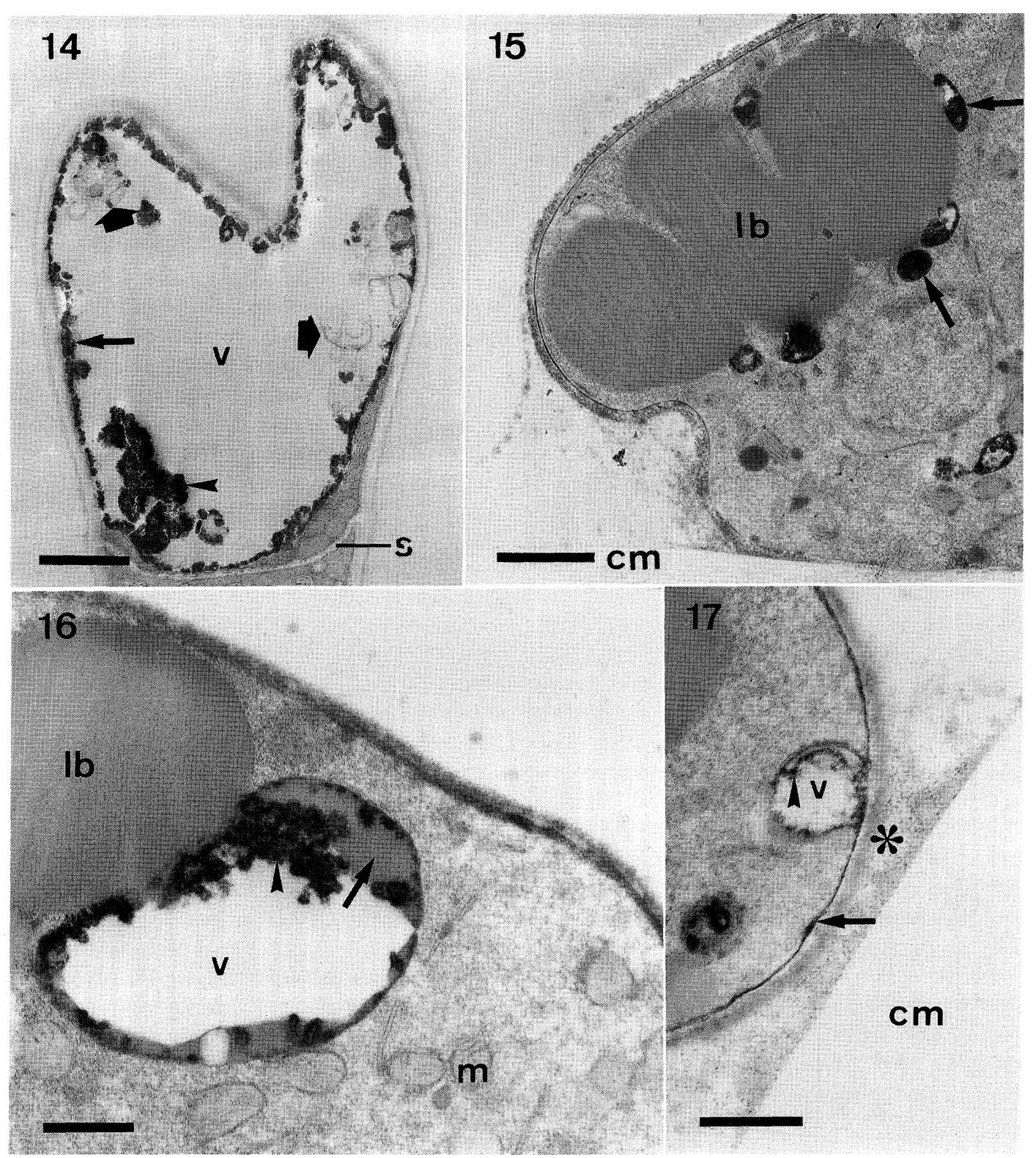

Figs. 14-17. Acid phosphatase reaction product during germination. Fig. 14. Germinated conidium exhibiting a large vacuole (v). Acid phosphatase reaction product is associated with the vacuolar membrane (arrow) and present in the vacuolar lumen (arrow tip). A septum (s) dividing the conidium is observed. Note the diversified components that present membranous debris contained in the lumen (thick arrows). Bar $=2$ $\mu \mathrm{m}$. Fig. 15. Appressorium exhibiting the reaction product in vesicles associated with lipid bodies (arrows). Note the very close juxtaposition between vesicles and lipids. Cellophane membrane $(\mathrm{cm})$ is observed. Bar $=1 \mu \mathrm{m}$. Fig. 16. Large appressorial vesicle (v) juxtaposed to the lipid bodies (lb). Acid phosphatase reaction product (arrow tip) and lipid material (arrow) are present in the lumen of the vesicle. Note the close contact between lipid material and vesicle. Mitochondria $(\mathrm{m})$ are observed. Bar $=500 \mathrm{~nm}$. Fig. 17. Acid phosphatase secretion in the appressorium. The acid phosphatase reaction product (arrow tip) inside the vesicle (v) is continuous with the cellular surface (arrow). Note the acid phosphatase reaction product present in the extracellular matrix (asterisk). Cellophane membrane $(\mathrm{cm})$ is observed. Bar $=400 \mathrm{~nm}$.

concerned with acid phosphatase activity during germination in fungi $(25,35)$. Our results demonstrate that, in $C$. graminicola, acid phosphatase activity is mainly localized in the vacuolar system in ungerminated and germinated conidia, and in the appressoria. The pre- sence of acid phosphatase, together with morphological evidences, suggest a digestive function for these cellular structures. Acid phosphatase has been classically considered as the marker enzyme for lysosomes (27). Lysosomal function was attributed to microbial vacu- 
oles, which exhibited the activity of this enzyme, in Sclerotinia fructigena (13), Saccharomyces cerevisiae (31), Sclerotium rolfsii (11) and Aspergillus flavus (2). Nevertheless, fungi vacuoles are also involved in a variety of physiological functions (15).

Vacuolation of germinated conidium and the presence of cellular debris inside the vacuoles suggest an autophagic process. An increase in autophagy is classically known to happen when the cells are exposed to different stresses, submitted to a great metabolic overload or extensive cellular remodeling $(1,4,9,34)$.

In the appressoria, the proximity between vesicles and lipid bodies and the presence of lipid material inside these vesicles (Figs. 15-16) indicate involvement of these compartments in lipid mobilization. However, vesicle-lipid interaction and lipid internalization mechanism are not clear. In the appressoria, the reaction product of acid phosphatase was not restricted to the vacuolar system, but was also present in secretory vesicles, and the cell surface and extracellular matrix (Fig. 17). Fungi and yeast secrete acid phosphatase $(10,24)$ and this enzyme is demonstrated in the cell wall and periplasmic space $(2,18,35)$. The secreted enzyme may hydrolyze phosphate esters, resulting from degradation of organic compounds in nature (25). Specifically, during germination, acid phosphatase was secreted by Neurospora crassa (25) and in Candida albicans the activity of this enzyme may have disappeared from the conidial surface and be transferred to the germ tube cell wall (35). These authors suggested that the enzyme may be involved in phosphoprotein dephosphorylation during cell wall reorganization.

We presently use deposition of the acid phosphatase reaction product as a marker to study the vacuolar system in C. graminicola and to describe the intake of cellular components into the vacuoles. Our data indicate that ungerminated conidia vacuoles and appressoria vesicles are lytic compartments and demonstrate that the mechanism of the lipid body uptake in ungerminated conidia is analogous to microautophagy. Germination is characterized by hydrolysis of reserves from the storage tissue. Knowledge of the cellular processes involved in intracellular digestion can contribute to the understanding of mechanisms of germination regulation in fungi.

Acknowledgments. We thank Marco A. Randi for his technical advice on lipid staining. We thank Dr. Philip A.J. Gorin and Dr. Marshall Yates for their comments regarding the manuscript. This research was supported in part by grants from the Brazilian National Research Council CNPq, PRONEX and FUNPAR.

\section{REFERENCES}

1. Baba, M., Takeshige, K., Baba, N., and Ohsumi, Y. 1994.
Ultrastructural analysis of the autophagic process in yeast: detection of autophagosomes and their characterization. J. Cell Biology, 124: 903-913.

2. Bojovic-Cvetic, D. and Vujicic, R. 1982. Acid phosphatase and distribution in Aspergillus flavus. Trans. Br. Mycol. Soc., 79: 137-141.

3. BuCHI, D.F. and SouzA, W. 1992. Internalization of surface components during ingestion of Saccharomyces cerevisiae by macrophages. J. Submicrosc. Cytol. Pathol., 24: 135-141.

4. BuCHER, F. and Hofer, R. 1993. Histological and enzyme histochemical changes in the kidney of male bullhead (Cottus gobio) during the spawning period. Journal of Fish Biology, 42: 403-409.

5. Chiang, H.L., Schekman, R., and Hamamoto, S. 1996 . Selective uptake of cytosolic, paroxysmal and plasma membrane proteins into yeast lysosome for degradation. J. Biol. Chem., 271: 9934-9941.

6. Culling, C.F.A. 1983. Handbook of histopathological and histochemical techniques. Third ed. Butterworth and Co. Ltd. London, United Kingdon. 361pp.

7. Gaspar, M.L., Pollero, R.J., and Cabello, M.N. 1994. Triacylglycerol consumption during spore germination of vesicular-arbuscular mycorrhizal fungi. JAOCS, 71: 449-452.

8. González, F.J., Fauste, C., Burguilo, F.J., and Dominguez, A. 1993. Kinetic behavior of a repressible acid phosphatase from the yeast Yarrowia lipolytica: a comparative study between the solubilized enzyme, the enzyme bound to cell-wall fragments and the enzyme bound to intact cells. Biochim. Biophys. Acta, 1162: 17-27.

9. Gunawardana, V.K. 1992. Lysosomes in the seminiferous tubules of the domestic fowl as revealed by acid phosphatase activity. Acta. Histochem. Cytochem., 25: 91-96.

10. Han, S.W., Michelin, M.A., Barbosa, J.E., and Rossi, A. 1994. Purification and constitutive excretion of acid phosphatase in Neurospora crassa. Phytochemistry, 35: 1131-1135.

11. Hänssler, G., MaXweel, D.P., and MaXweel, M.D. 1975. Demonstrations of acid phosphatase-containing vacuoles in hyphal tip cells of Sclerotium rolfsii. J. Bacteriol., 124: 997-1006.

12. Herman, E.M., Baumgartner, B., and Chrispeels, M. 1981. Uptake and apparent digestion of cytoplasmic organelles by protein bodies (protein storage vacuoles) in mung bean cotyledons. Eur. J. Cell Biol., 24: 226-235.

13. Hislop, E.C., Barnaby, V.M., Shellis, C., and Laborda, F. 1974. Localization of $\alpha$-L-arabinofuranosidase and acid phosphatase in mycelium of Sclerotinia fructigena. J. Gen. Microbiol., 81: 19-99.

14. Kerrigan, J. and Mims, C.W. 1993. Ultrastructural and cytochemical investigations of the fungus Colletotrichum gloeosporioides, causal organism of pecan anthracnose. The BEAM Newsletter of the Southeastern Electron Microscopy Society, 9: 21-25.

15. Kulonsky, D.J., Herman, P.K., and EmR, S.D. 1990. The fungal vacuole: composition, function and biogenesis. Microbiol. Rev., 54: 266-292.

16. LeIte, B. 1992. Production of mycosporine-alanine, acetic acid and uridine by cultures of Colletotrichum graminicola: their role in conidial maturation and development. West Lafayette. $\mathrm{PhD}$ thesis, Purdue University.

17. Leite, B. and Nicholson, R.L. 1992. Mycosporine-alanine: a self-inhibitor of germination from the conidial mucilage of $\mathrm{Col}$ letotrichum graminicola. Exp. Mycol., 16: 76-86.

18. Linnemans, W.A.M., Boer, P., and Elbers, P.F. 1977. Localization of acid phosphatase in Saccharomyces cerevisiae: a 
clue to cell formation. J. Bacteriol., 131: 638-644.

19. Maia, L.C., Kimbrough, J.W., and BenNy, G.L. 1994. Ultrastructure of spore germination in Gigaspora albida (Glomales). Mycologia, 86: 343-349.

20. Maxwell, D.P., Armentrout, V.N., and Graves, Jr. L.B. 1977. Microbodies in plant pathogenic fungi. Ann. Rev. Phytopathol., 15: 119-134.

21. Meirelles, M.N.L. and SouzA, W. 1986. The fate of plasma membrane macrophage enzyme markers during endocytosis of Trypanosaoma cruzi. J. Submicros. Cytol. Pathol., 18: 99-107.

22. Mims, C.W., TAYlor, J., and Richardson, E.A. 1989. Ultrastructure of the early stages of infection of peanut leaves by the rust fungus Puccinia arachidis. Can. J. Bot., 67: 3570-3579.

23. Mims, C.W., Richardson, E.A., Clay, R., and Nicholson, R.L. 1995. Ultrastructure of conidia and the conidium aging process in the plant pathogenic fungus Colletotrichum graminicola. Int. J. Plant. Sci., 156: 9-18.

24. Nahas, E., Terenzi, H.F., and Rossi, A. 1982. Effect of carbon source and $\mathrm{pH}$ on the production and secretion of acid phosphatase (EC 3.1.3.2.) and alkaline phosphatase (EC 3.1.3.1) in Neurospora crassa. J. Gen. Microbiol., 128: 2017 2021.

25. NaHAs, E. 1989. Control and localization of phosphatases in conidia of Neurospora crassa. Can. J. Microbiol., 35: 830-835.

26. Nicholson, R.L., Hipskind, J., and HanaU, R.M. 1989. Protection against phenol toxicity by the spore mucilage of Colletotrichum gaminicola, an aid to secondary spread. Physiol. Mol. Plant Pathol., 35: 243-252.

27. Novikoff, A.B. 1976. The endoplasmic reticulum: a cytochemist's view (A review). Proc. Natl. Acad. Sci. USA, 73: 2781-2787.

28. O'Connell, R.J., Bailey, A., and Richmond, V. 1985. Cytology and physiology of infection of Phaseolus vulgaris by Colletotrichum lindemuthianum. Physiol. Plant. Pathol., 27: 7598.

29. Politis, D.J. 1976. Utrastructure of penetration by Colletotrichum graminicola of highly resistant oat leaves. Physiol. Plant. Pathol., 8: 117-122.
30. Politis, D.J. and WheELER, H. 1973. Ultrastructural study of penetration of maize leaves by Colletotrichum graminicola. Physiol. Plant. Pathol., 3: 465-471.

31. RiJn, H.J.M., Linnemans, W.A.N., and BoeR, P. 1975. Localization of acid phosphatase in protoplasts from Saccharomyces cerevisiae. J. Bacteriol., 123: 1144-1149.

32. RuCH, D.G. and MotTA, J.J. 1987. Ultrastructure and cytochemistry of dormant basidiospores of Psilocybe cubensis. Mycologia, 79: 387-398.

33. Sangwan, R.S., Mathivet, V., and Vasseur, G. 1989. Ultrastructural localization of acid phosphatase during male meiosis and sporogenesis in Datura: evidence for digestion of cytoplasmic structures in the vacuoles. Protoplasma, 149: 36-46.

34. Takeshige, K., Baba, M., Tsuboi, S., Noda, T., and Ohsumi, Y. 1992. Autophagy in yeast demonstrated with proteinase-deficient mutants and conditions for its induction. J. Cell Biol., 119: $301-311$.

35. Tronchin, G., Bouchara, J.P., and Robert, R. 1989. Dynamic changes of the cell wall surface of Candida albicans associated with germination and adherence. Eur. J. Cell Biol., 50: 285-290.

36. Tuttle, D.L. and DunN, JR. W.A. 1995. Divergent modes of autophagy in the methylotrophic yeast Pichia pastoris. J. Cell Sci., 108: 25-35.

37. VAN DyKe, C.G. and Mims, C.W. 1991. Ultrastructure of conidia, conidium germination, and appressorium development in the plant pathogenic fungus Colletotrichum truncatum. Can. J. Bot., 69: 2455-2467.

38. WeEte, J.E. 1974. Fungal lipid biochemistry. New York, Plenum Press. 12pp.

39. Wilson, C.L., Junper, G., and Mason, D.L. 1980. Vacuole dynamics in fungal pathogens. Phytopathol., 70: 783-788.

40. Yuan, W., Tuttle, D.L., Shi, Y-J., RalPh, G.S., and DunN, JR. A. 1997. Glucose-induced microautophagy in Pichia pastoris requires the $\alpha$-subunit of phosphofructokinase. J. Cell Biol., 110: 1935-1945.

(Received for publication, May 25, 1998

and in revised form, September 17, 1998) 